\title{
Avaliação de mapas de transporte coletivo em terminais urbanos de ônibus da cidade de Curitiba
}

\author{
Evaluation of public transport maps in urbane bus terminals in Curitiba \\ Audrey Cristine Crocetti Sommavilla, Stephania Padovani
}

orientação, mapas de transporte, avaliação

\begin{abstract}
Esta pesquisa investigou a qualidade gráfico-informacional e a eficácia comunicacional do mapa da RIT URBS (Rede Integrada de Transporte) disponível em Terminais de Transporte Coletivo da cidade de Curitiba. Visando atingir tal objetivo, realizou-se um estudo analítico (para identificar as características e deficiências gráfico-informacionais do mapa), seguido de entrevistas com 70 usuários em terminais de transporte coletivo. Os resultados revelaram que o mapa apresenta diversas falhas, o que ocasiona seu abandono pelos usuários, tornando este sistema de informações algo obsoleto nos locais onde se encontra.
\end{abstract}

orientation, transport maps, evaluation

This study investigated the quality of the information depicted and the communicational effectiveness of the RIT-URBS map, available at public transport terminals in Curitiba. In order to achieve such purpose, we conducted an analytical study (to identify graphical and informational problems), followed by interviews with 70 users in public transport terminals. The results demonstrated that the map has several problems, which lead it to be ignored by passengers, becoming an obsolete information system in the places where it is located.

\section{Introdução}

Com o crescimento das cidades, artefatos gráficos comunicacionais que visam orientar os cidadãos de um local a outro de forma autônoma nos centros urbanos se tornam cada vez mais necessários. Entre esses artefatos, destacam-se os mapas turísticos, mapas com itinerários de linhas de transporte coletivo, totens digitais de informações, sites de informações das prefeituras, entre outros. Neste estudo, o objeto em questão é o mapa da Rede Integrada de Transporte (RITURBS) instalado em terminais de transporte coletivo da cidade de Curitiba.

A motivação para realização desta pesquisa surgiu a partir de algumas constatações das autoras em seu cotidiano, quanto aos problemas e dificuldades dos usuários deste sistema de transporte em sua interação com os mapas RIT-URBS. Observou-se, por exemplo, que as rotas das linhas de ônibus não são bem compreendidas, fazendo com que usuários prefiram pedir informações oralmente a outros transeuntes ou funcionários ao invés de consultar os mapas existentes. Mais ainda, na forma como o conteúdo do mapa está representado, linhas se confundem com outras informações fornecidas, tornando os nomes das linhas e cores dos ônibus (como são habitualmente, conhecidas pelos usuários de transporte coletivo de Curitiba) praticamente ilegíveis.

Neste contexto, a presente pesquisa tem como objetivo avaliar o mapa existente nos terminais de transporte coletivo de Curitiba. Para tanto, definiram - se como objetivos específicos: (a) identificar e delimitar os problemas gráficos e informacionais existentes no mapa RIT-URBS Terminal; (b) verificar as dificuldades enfrentadas pelos usuários do sistema de transporte coletivo; (c) propor diretrizes para o redesign do mapa RIT-URBS Terminal.

Através da observação de usuários realizando tarefas de orientação com o mapa de transporte coletivo RIT - URBS foi possível verificar como ocorre a percepção e compreensão do mapa, a eficácia na realização de tarefas de orientação e a preferência dos usuários no que tange à legibilidade, estética e usabilidade da apresentação gráfico informacional do mapa. 


\section{O sistema de informação para usuários do transporte coletivo de Curitiba}

A Rede Integrada de Transporte de Curitiba teve sua inauguração no ano de 1979, com a implantação da primeira linha de ônibus inter-bairros. As inovações no transporte corresponderam principalmente à introdução do "Ligeirinho", da Linha Direta, com maior distância entre estações e embarque em nível, estações tubo, e o ônibus bi-articulado com capacidade para 270 passageiros.

No Sistema de Transporte Coletivo de Curitiba os ônibus são identificados por cores (que distinguem os serviços oferecidos e os tipos de trajetos) e pelo nome das linhas, visando facilitar o deslocamento e entendimento pelos usuários (figura 01). Por exemplo, os ônibus de cor laranja alimentadores - partem dos terminais de ponta ou intermediários existentes ao longo dos eixos atendidos pelos expressos, circulam em torno dos terminais e bairros próximos à região destes terminais e nunca vão ao centro da cidade.

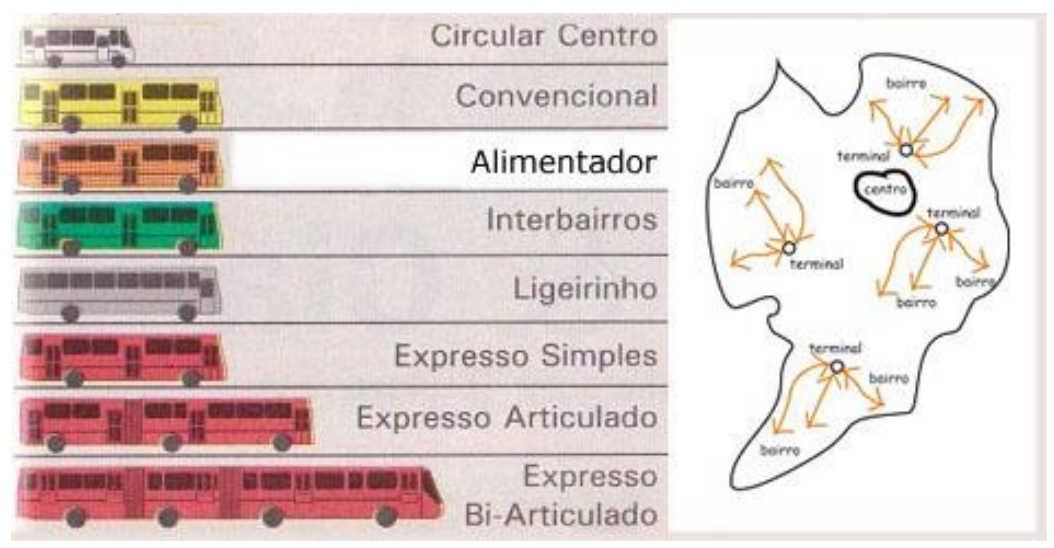

Figura 01: Codificação cromática dos ônibus e exemplo de tipo de trajeto

Para orientar a população na utilização do transporte coletivo foi criado um sistema de informações para usuários de ônibus em Curitiba. Este sistema é composto de várias alternativas, em diferentes formatos e suportes, como por exemplo: central 156, sistema URBS na web, site da PMC, mapa turístico impresso, mapa de itinerários de linhas de ônibus (RIT - URBS), totens de informação, letreiros luminosos com informação digital e informações sonoras, mapas lineares, placas de sinalização com nome das linhas (embarque e desembarque), bandeiras com nome de linhas em paradas e mapa com itinerários de linhas em terminais (vide tabela 1).

Quadro 01: Distribuição dos subsistemas de informação para usuários de ônibus de Curitiba

\begin{tabular}{|c|c|}
\hline Local de utilização & Subsistemas informacionais \\
\hline Centro & $\begin{array}{l}\text { - } \text { mapa RIT URBS para pontos de ônibus; } \\
\text { - bandeiras com linhas de ônibus (em pontos } \\
\text { de ônibus); } \\
\text { - } \text { totens informativos computadorizados; } \\
\text { - mapa linear (em estações tubo). }\end{array}$ \\
\hline $\begin{array}{l}\text { Terminais de } \\
\text { transporte coletivo }\end{array}$ & $\begin{array}{l}\text { - placas informativas de pontos de embarque e } \\
\text { desembarque; } \\
\text { - mapa de linhas de transporte coletivo (RIT } \\
\text { URBS); } \\
\text { - totens informativos computadorizados; } \\
\text { - mapa linear (em estações tubo). }\end{array}$ \\
\hline Praças & $\begin{array}{l}\text { - } \text { totens informativos computadorizados; } \\
\text { - } \text { desembarque; } \\
\text { - mapa RIT URBS para pontos de ônibus; }\end{array}$ \\
\hline
\end{tabular}




\begin{tabular}{|c|c|}
\hline & $\begin{array}{l}\text { bandeiras com linhas de ônibus (em pontos } \\
\text { de ônibus); }\end{array}$ \\
\hline Pontos turísticos & $\begin{array}{l}\text { - } \quad \text { totens informativos computadorizados; } \\
\text { - mapa RIT URBS para pontos de ônibus; } \\
\text { - bandeiras com linhas de ônibus (em pontos } \\
\text { de ônibus); }\end{array}$ \\
\hline Ônibus (interior) & $\begin{array}{l}\text { - letreiros luminosos com informação sobre } \\
\text { estações e segurança nos ônibus; } \\
\text { sistema de mensagens sonoras com } \\
\text { informações sobre estações, portas de } \\
\text { embarque e desembarque, conexões e } \\
\text { segurança nos ônibus. }\end{array}$ \\
\hline Internet & $\begin{array}{l}\text { - } 156 \text { na web; } \\
\text { - } \quad \text { site PMC (Prefeitura Municipal de Curitiba); } \\
\text { - } \text { site 'Sou ligado a Curitiba'; } \\
\text { - site da URBS (Urbanização de Curitiba S.A.). }\end{array}$ \\
\hline
\end{tabular}

Considerando o foco deste estudo no mapa de transporte coletivo RIT-URBS Terminal, apresentamos a seguir alguns exemplos de mapas utilizados no sistema de informação para usuários de transporte coletivo de Curitiba

\section{Mapa de itinerários de ônibus RIT-URBS}

Os mapas de itinerários de linhas de ônibus estão localizados em pontos de ônibus. Indicam a localização de parques, pontos de ônibus, itinerários de ônibus com número das linhas e nomes de ruas. Detalham a região específica (1 km em torno da parada de ônibus específica) com ícones de ônibus com o número das linhas inseridas (figura 03).

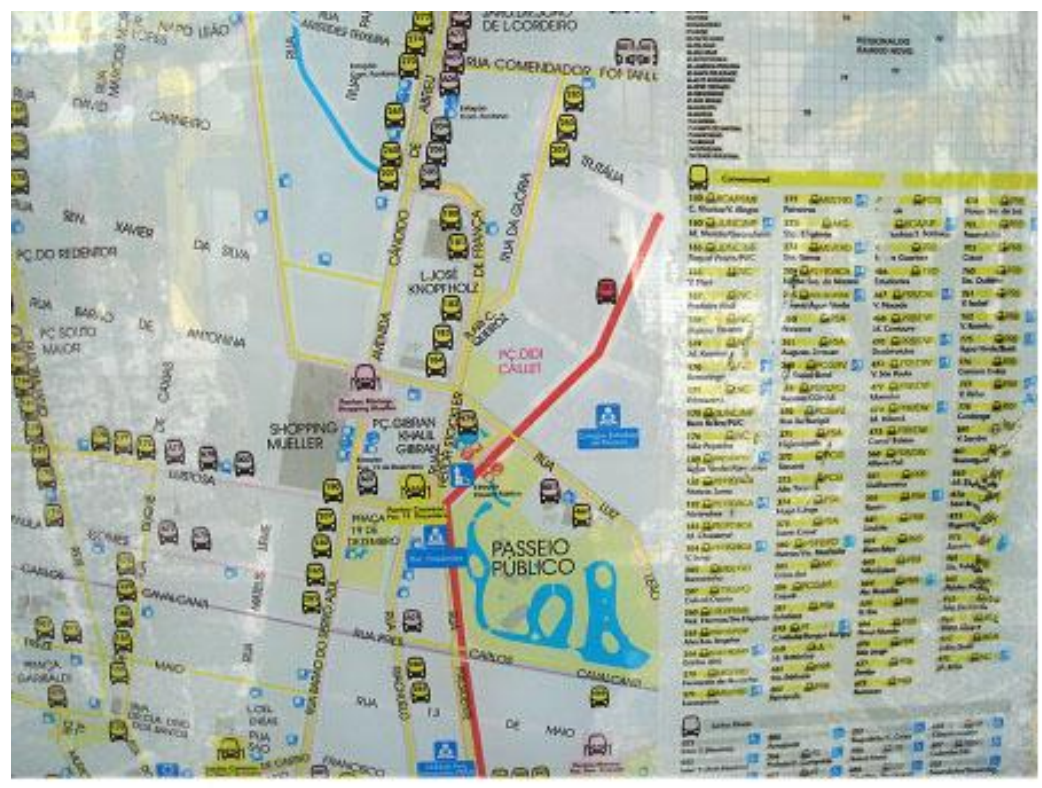

Figura 02: Detalhe do mapa de itinerários de ônibus RIT-URBS

\section{Mapa linear em estações tubo}

O mapa linear localizado dentro de estações tubo especifica as estações da linha correspondente e destaca o local onde o usuário está em cor verde e rótulo "Você está aqui". Apresenta ainda as estações onde são feitas conexões de linhas de ônibus (figura 04). 


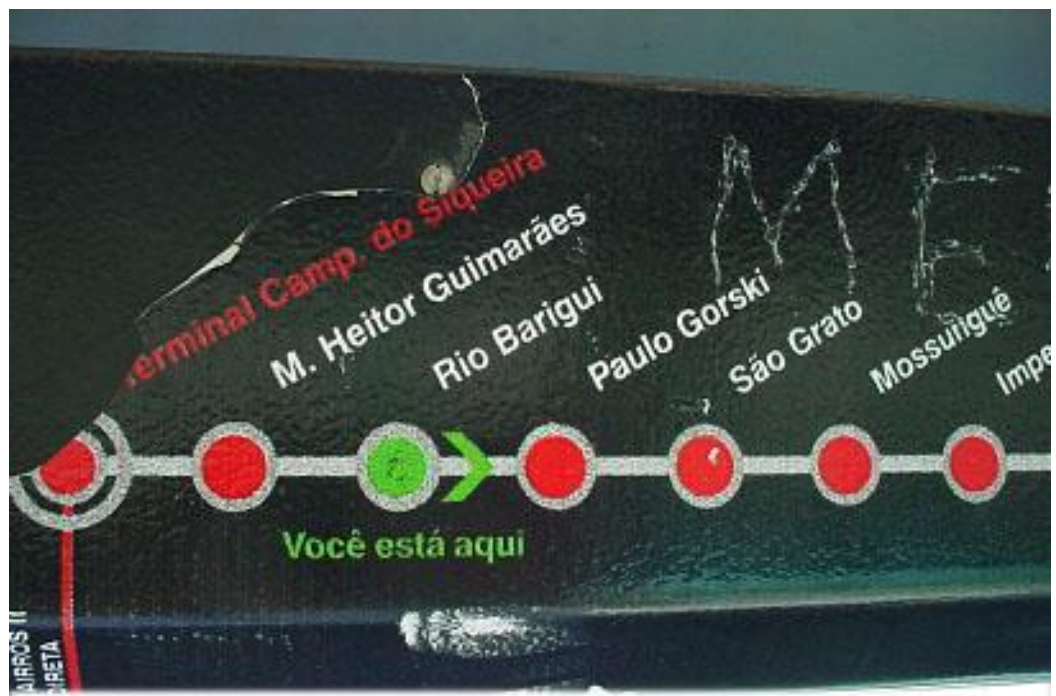

Figura 03: Parte de um mapa linear em estação tubo

\section{Mapa da rede integrada de transporte RIT-URBS terminal}

Os mapas da RIT-URBS terminal estão localizados em terminais de transporte coletivo da cidade de Curitiba. Utilizam a base do mapa geopolítico de Curitiba com anel metropolitano. Mostram linhas de ônibus com legenda de cores correspondentes às cores dos ônibus, áreas verdes, parques, delimitação metropolitana, rios, vias principais, nome das estações tubo, nome das linhas de ônibus, nome dos terminais, grade de quadras e legenda (figura 05).

O mapa RIT-URBS foi escolhido como objeto de estudo desta pesquisa por conjugar um número grande de informações, por estar localizado em todos os terminais de transporte coletivo da cidade e atingir uma grande quantidade de usuários.

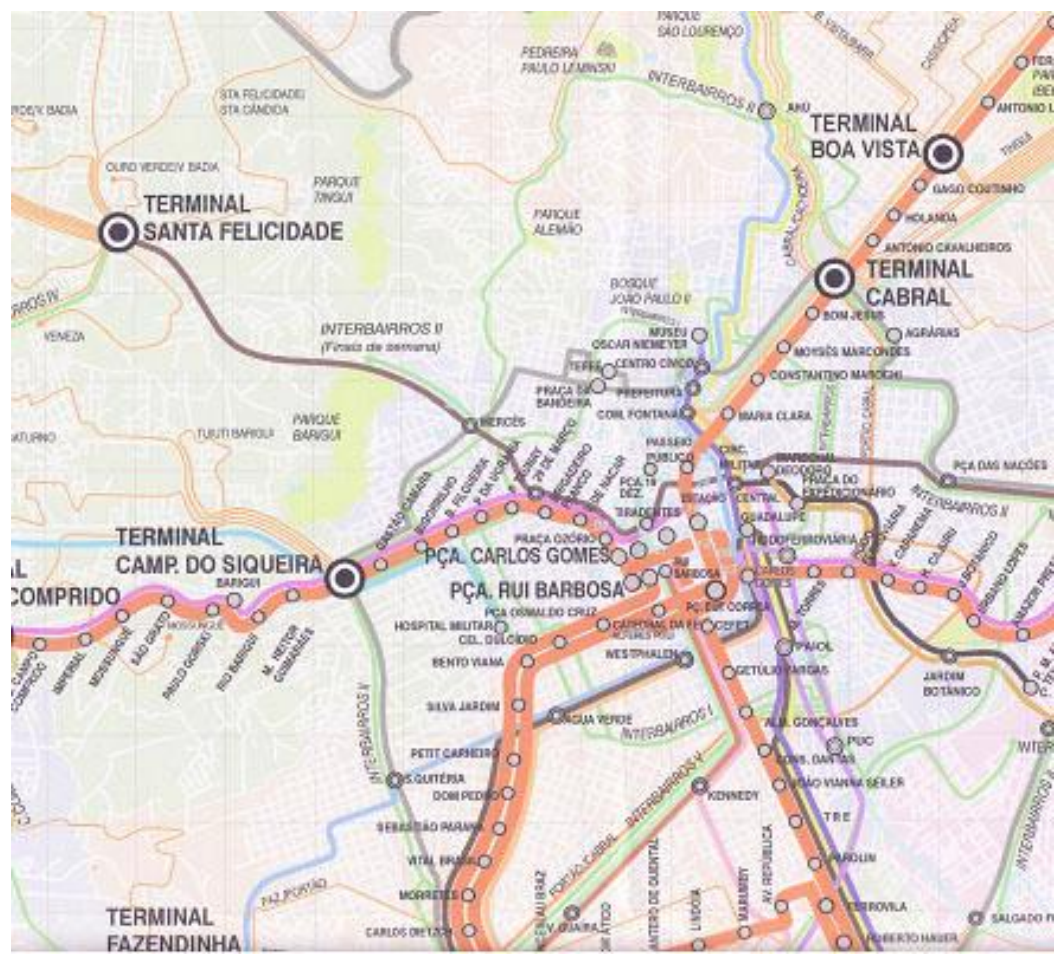

Figura 04: Detalhe do mapa RIT-URBS terminal 


\section{Mapas como sistemas gráficos de orientação espacial}

\section{Conceituação de mapas}

Mapas são representações gráficas que descrevem aspectos do ambiente geográfico em uma escala espacial expressivamente menor que a original. Klippel et al. (2005) ressaltam que para manter uma boa legibilidade dessas características geográficas em dimensões tão reduzidas, a representação necessita ser simplificada de forma a 'encaixar' todas as informações necessárias e, ainda assim, manter sua eficácia comunicacional. Pelas razões anteriormente descritas, os autores denominam essas representações como esquemáticas.

De acordo com Mijksenaar (1999), mapa é um instrumento que deve dar suporte à realização de uma tarefa específica. Por exemplo: chegar a um terminal de transporte coletivo e tomar um ônibus de uma linha desejada sem precisar consultar nenhum funcionário do local. Segundo Mijksenaar (1999), o objetivo principal de um mapa é fazer com que o usuário ao consultá-lo escolha a rota correta para um destino e localize-se em um ambiente desconhecido.

Problemas de orientação podem ser extremamente estressantes dependendo da circunstância na qual o usuário se encontra (VENEMANS, 1994). Segundo Passini (1998), a desorientação pode trazer sentimentos de ansiedade, insegurança e frustração. Ela é conseqüência da falta de um mapa cognitivo ou da incapacidade de se desenvolver um plano de ação para chegar a algum lugar. $\mathrm{O}$ autor afirma ainda que, quando as pessoas não conseguem navegar satisfatoriamente, este descontentamento é revertido à qualidade dos serviços oferecidos naquele ambiente.

O’Neill (1994) acrescenta que problemas de orientação também podem resultar de sistemas de sinalização mal projetados. Estes fatores influenciam a navegação. Se o usuário não sabe onde está, nem qual rota deve escolher para chegar aonde deseja, provavelmente não atingirá seu objetivo, ou perderá muito tempo em sua busca.

\section{Orientação espacial (wayfinding) e desenvolvimento de mapas cognitivos}

Wayfinding, ou orientação espacial é a habilidade mental da pessoa de se imaginar e representar a configuração física e se situar especialmente dentro desta representação (SPINILLO,2007). Conforme Passini (1994), o termo engloba todos os processos perceptuais, cognitivos e comportamentais envolvidos na busca do destino desejado.

Benelli et al. (2001) definem orientação como o conhecimento do espaço que nos cerca, somado à localização de objetos importantes no ambiente. Ela é decisiva para encontrarmos o caminho de um ponto a outro. Já para Hunt (1994), a orientação é: "a ciência de organizar e definir uma seqüência de mensagens de modo a tornar um prédio ou espaço o mais auto circulável possível".

Satalich (1995) propôs quatro passos para o processo de orientação/navegação quando o usuário busca uma localidade específica em ambientes físicos:

[a] orientação: reconhecer sua localização em relação aos objetos vizinhos e o local/meta onde deseja chegar;

[b] decisão da rota: selecionar uma rota que conduza ao local da meta;

[c] monitoramento da rota: monitorar a rota selecionada para conferir se ela está levando ao objetivo esperado;

[d] reconhecimento do destino: reconhecer que chegou (ou está bem próximo) ao local desejado.

O processo de navegação em ambientes (físicos ou informacionais) é acompanhado do desenvolvimento de uma representação mental englobando informação sobre as características dos locais visitados e as relações entre esses locais. Essa representação é denominada mapa 
cognitivo (CALVI, 1997). Conforme Lynch (2006):

"Cada indivíduo tem uma imagem própria e única que, de certa forma, raramente ou mesmo nunca é divulgada, mas que, contudo, se aproxima da imagem pública e que em meios ambientes se torna mais ou menos determinante, mais ou menos aceite".

Lynch explanava que "estruturar e identificar o ambiente é uma capacidade vital entre todos os animais que se locomovem". Estudando os mapas cognitivos, o autor identificou cinco elementos físicos que constroem a imagem da cidade: [a] vias - caminhos, [b] limites - fronteiras, [c] bairros - regiões, [d] cruzamentos - nós e [e] pontos de referência.

\section{Recomendações para o uso de mapas em sistemas de orientação}

Durante o processo de fundamentação deste estudo, buscaram-se, na literatura de Petterson (2007), O’Neill (1994), Hunt (1994), Passini (1994), Pheasant (1987), Devlin \& Bernstein (1997) recomendações para a aplicação de mapas em sistema gráficos de orientação. A seguir, apresentamos as recomendações mais relevantes para a presente pesquisa:

[a] As pessoas necessitam ver a mesma informação várias vezes para confirmar suas expectativas e entendê-la. Crie um circuito de informação envolvendo mapas gerais, sinalização de circulação e sinalização de localização;

[b] Trabalhe de forma integrada com o contexto arquitetural (utilize elementos arquitetônicos em destaque como pontos de referência nos mapas e posicione a sinalização próxima a esses pontos);

[c] Utilize mapas de visualização geral para situações em que os usuários visitam repetidamente o ambiente e/ou visitam vários locais dentro do mesmo ambiente. Mapas são úteis para comunicar a organização geral do ambiente e completar/confirmar o mapa cognitivo do usuário;

[d] Em mapas de visualização geral ou parcial, nomeie os pontos de referência no próprio mapa sempre que possível, ao invés de utilizar numeração e legenda;

[e] Utilize mapas que indiquem a forma do local, diferenciem as áreas graficamente, mas não apresentem excesso de detalhes que confundam o usuário;

[f] Em mapas de visualização geral, indique sempre a posição atual do usuário e destaque pontos de referência;

[g] Utilize a cor com significado e associada a símbolos ou texto. Evite excesso de cores ou cores muito parecidas em termos de matiz;

[h] Utilize legendas para explicar o código cromático ou abreviações utilizadas nos mapas de visualização geral;

[i] Considere o vocabulário da população usuária para escolher os termos a serem utilizados nos enunciados.

\section{Método da pesquisa}

Esta pesquisa divide-se em duas fases principais, sendo a primeira de caráter analítico e a segunda de caráter empírico. Nesta seção, apresentamos os modelos, métodos e procedimentos utilizados em cada fase.

\subsection{Fase 1 | estudo analítico do mapa RIT-URBS}

Nesta fase da pesquisa, o mapa RIT-URBS foi avaliado pelas próprias pesquisadoras com base em princípios de design da informação. A partir das recomendações para o design de mapas de Mijksenaar (1999), O'Neil (1999) e princípios de design de Petterson (2007) desenvolveu-se a seguinte lista de critérios para avaliação do mapa de transporte coletivo RIT-URBS. 
Quadro 02: Critérios utilizados na avaliação do mapa RIT-URBS terminal

\begin{tabular}{|c|c|}
\hline Local de utilização & Subsistemas informacionais \\
\hline Acesso & $\begin{array}{l}\text { Posicionar os mapas (e sinalização de } \\
\text { circulação) em pontos de decisão no } \\
\text { ambiente (e.g., bifurcações, intersecções } \\
\text { entre corredores). }\end{array}$ \\
\hline $\begin{array}{l}\text { Utilização / } \\
\text { manipulação }\end{array}$ & $\begin{array}{l}\text { A orientação do mapa deve refletir o ponto de } \\
\text { vista do usuário ao observá-lo em relação ao } \\
\text { ambiente. }\end{array}$ \\
\hline Conteúdo & $\begin{array}{l}\text { - Incluir pontos de referência (landmarks) que } \\
\text { auxiliem na tarefa de orientação; } \\
\text { - Evitar excesso de detalhes, apresentando } \\
\text { apenas informação suficiente sobre o layout } \\
\text { do ambiente para localizar e orientar o } \\
\text { usuário. }\end{array}$ \\
\hline $\begin{array}{l}\text { Representação da } \\
\text { estrutura }\end{array}$ & $\begin{array}{l}\text { - Utilizar mapas em perspectiva somente } \\
\text { quando diminuir a complexidade do desenho. } \\
\text { Em geral, a vista em planta é preferida. }\end{array}$ \\
\hline $\begin{array}{l}\text { Apresentação da } \\
\text { informação }\end{array}$ & $\begin{array}{l}\text { - Combinar layers (camadas) de informação de } \\
\text { forma distinta, mas ainda harmoniosa; } \\
\text { - Combinar escala do mapa com uma grid (e.g., } \\
\text { cada aresta da grid= } 15 \text { minutos a pé); } \\
\text { - Usar cores no fundo, tamanho de letras e } \\
\text { tipos para aumentar a eficácia da orientação; } \\
\text { - Obedecer a convenções cromáticas (e.g., azul } \\
\text { para água, verde para parques); } \\
\text { - Minimizar a quantidade de texto. O mapa } \\
\text { deve funcionar independentemente do texto; } \\
\text { - Explicar símbolos no mapa (legenda) e dar } \\
\text { preferência a símbolos internacionais; } \\
\text { - Destacar o sinalizador de 'você está aqui' } \\
\text { dentro do mapa esquemático. }\end{array}$ \\
\hline Atualização & $\begin{array}{l}\text { - Construir os mapas com flexibilidade, caso } \\
\text { haja necessidade de mudança. }\end{array}$ \\
\hline $\begin{array}{l}\text { Princípios } \\
\text { funcionais }\end{array}$ & $\begin{array}{l}\text { - Estrutura; } \\
\text { - Clareza; } \\
\text { - Simplicidade; } \\
\text { - Ênfase; } \\
\text { - Unidade. }\end{array}$ \\
\hline $\begin{array}{l}\text { Princípios } \\
\text { cognitivos }\end{array}$ & $\begin{array}{l}\text { - Atrair a atenção; } \\
\text { - Facilitar a percepção (detecção e } \\
\text { identificação); } \\
\text { - Auxiliar a memória. }\end{array}$ \\
\hline
\end{tabular}

As pesquisadoras avaliaram o mapa individualmente verificando se cada recomendação havia sido aplicada no design do mapa. Em caso negativo, descreveram e ilustraram o problema observado no mapa em questão.

\subsection{Fase 2 | avaliação do mapa RIT-URBS terminal com usuários}


Esta fase da pesquisa foi realizada em 07 terminais de transporte coletivo da cidade de Curitiba: Terminal do Cabral, Terminal Capão da Imbuia, Terminal Hauer, Terminal Boqueirão, Terminal Pinheirinho, Terminal Capão Raso e Terminal Portão. Conduziram-se 70 entrevistas (10 em cada terminal), aplicadas com usuários de transporte coletivo, de todos os grupos etários.

\section{Perfil dos participantes}

Participaram voluntariamente da pesquisa 70 usuários do Sistema de Transporte Coletivo da cidade de Curitiba sendo $50 \%$ do sexo masculino e $50 \%$ do sexo feminino.

Quanto à faixa etária, $63 \%$ dos entrevistados tinham entre 15 e 34 anos, $26 \%$ estão na faixa de 35 a 54 anos e $11 \%$ na faixa de 55 anos ou mais.

No que se refere à escolaridade, $53 \%$ dos entrevistados tinham o segundo grau (incompleto ou completo), $36 \%$ dos entrevistados tinham o primeiro grau (incompleto ou completo) e $21 \%$ dos entrevistados tinham o curso superior (completo ou incompleto).

Em relação ao setor de atuação, 55\% dos entrevistados estavam concentrados na área de serviços; $17 \%$ no comércio; $10 \%$ eram exclusivamente estudantes; $7 \%$ estavam concentrados na área da indústria e $11 \%$ em outras categorias (e.g., desempregados, pensionistas, aposentados).

Por fim, quanto ao local de moradia, $63 \%$ dos entrevistados concentram-se na região sul da cidade de Curitiba; $16 \%$ na região leste e $7 \%$ em cada uma de três regiões: norte, oeste e central.

\section{Técnicas de coleta de dados}

A pesquisa de campo foi realizada utilizando-se as técnicas de entrevista semi-estruturada e observação sistemática, no próprio local onde se encontra o objeto de estudo (mapa RIT-URBS). A entrevista incluiu perguntas objetivas e de opinião, sendo conjugada com a observação da realização de duas tarefas de busca de informação e orientação utilizando o mapa.

A primeira tarefa solicitada foi que o usuário mostrasse onde ele estava no mapa. Na segunda tarefa, solicitou-se que o usuário encontrasse o seu destino no mapa. Ao final, alguns entrevistados deixaram suas sugestões para melhorar a apresentação gráfica e o conteúdo informacional do mapa RIT-URBS.

Cada participante foi entrevistado individualmente, e suas respostas foram anotadas em um formulário. A pauta da entrevista incluiu os seguintes itens:

[a] forma de identificação do ônibus;

[b] o que ou a quem o usuário consulta quando existem dúvidas sobre ônibus;

[c] se o usuário já utilizou o mapa exposto;

[d] como o usuário identifica o local onde está no mapa exposto;

[e] compreensão do mapa ao procurar uma determinada linha;

[f] o que exatamente atrapalha no mapa em questão;

[g] o que o usuário mudaria no mapa;

[h] sexo, idade, grau de escolaridade;

[i] ocupação atual, renda;

[j] local de moradia;

[k] opinião detalhada sobre o mapa em aspectos como: material utilizado, cores, tamanho do mapa, tamanho das letras e quantidade de informações existentes;

[l] sugestões e observações adicionais.

\section{Resultados da pesquisa}

O mapa RIT-URBS encontra-se localizado na área interna dos terminais de transporte coletivo de Curitiba dentro de totens metálicos com vidro transparente por fora. Tem aproximadamente a largura de $1.00 \mathrm{~m}$ e altura de $2.00 \mathrm{~m}$. Quanto ao acesso, o mapa não está posicionado em pontos de decisão do ambiente do terminal. Encontra-se colocado perpendicularmente à plataforma, de 
perfil para o usuário que passa no corredor, e não de frente como deveria estar para melhorar a visualização (figura 05).

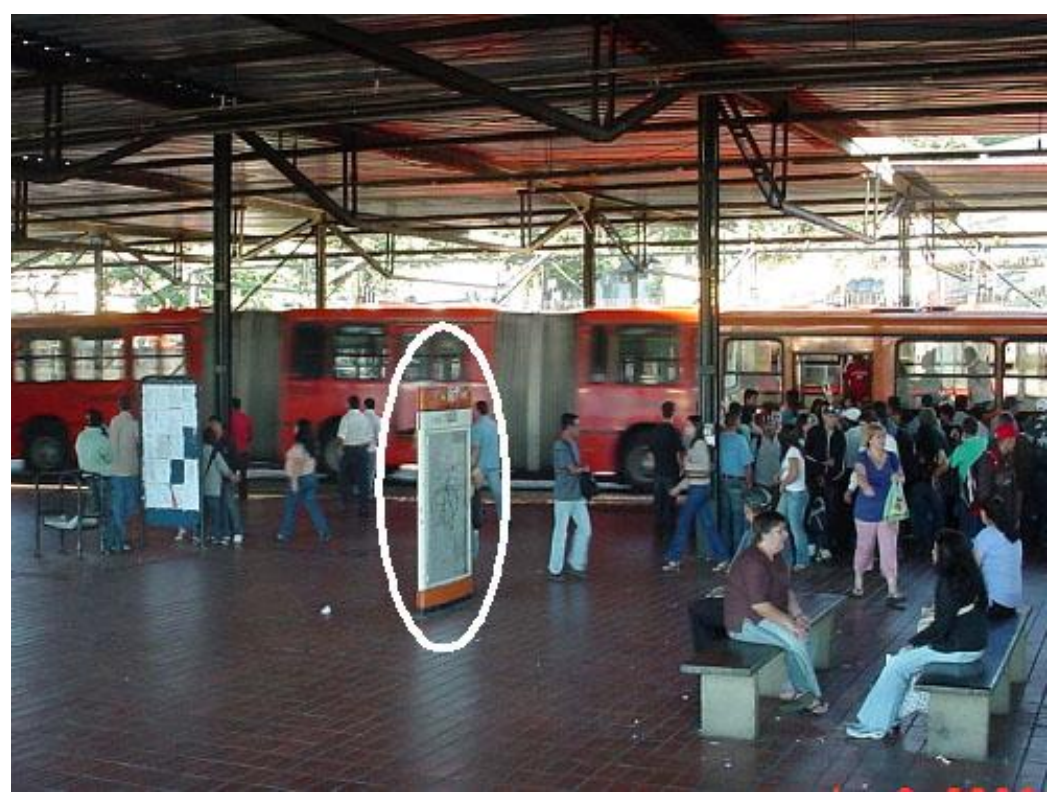

Figura 05: Posicionamento equivocado do mapa RIT-URBS nos terminais, prejudicando o acesso

Mais ainda, nos terminais de transporte coletivo não existe nenhuma indicação de onde o mapa possa ser consultado, prejudicando a busca de informações sobre a identificação das linhas de ônibus existentes no local. Cumpre mencionar que, nos terminais, o tempo é um fator crítico; por isso, os usuários dependem de informação pronta e correta das linhas e de rápido entendimento para não perder o horário do ônibus que o leva ao seu destino.

Quanto à utilização/manipulação o mapa não reflete o ponto de vista do usuário ao observá-lo em relação ao ambiente, pois geralmente está fixado em locais sem nenhuma direção específica, selecionados simplesmente porque são locais onde passa grande número de usuários do terminal.

Quanto ao conteúdo do mapa, este inclui as linhas de ônibus com diferenciação as cores dos ônibus do sistema de transporte integrado (amarelo-convencionais, vermelho-expresso, laranjaalimentadores, verde-interbairros). Entretanto, acrescentaram-se azul, rosa, lilás, cinza e marrom para diferenciar também as linhas do ônibus linha-direta. Esse excesso de linhas, representadas em cores sem convenção pré - estabelecida acabam confundindo ou mesmo fazendo com que o usuário não perceba que elas existem (figura 06). 


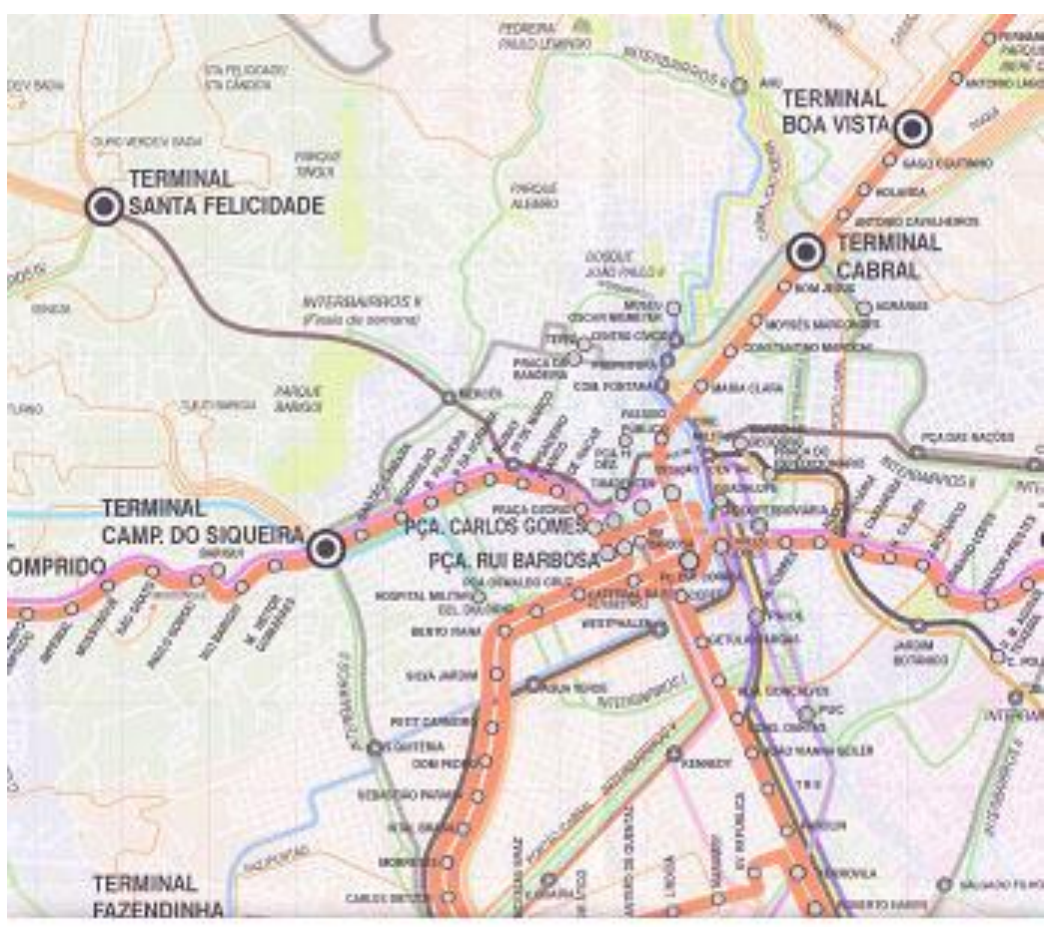

Figura 06: Excesso de linhas e cores sem convenção pré-estabelecida no mapa RIT-URBS terminal

Outra deficiência do mapa é a não inclusão de pontos de referência, como por exemplo, pontos turísticos que auxiliam na tarefa de orientação do usuário. Há claramente um excesso de detalhes (nomes de parques, nomes dos locais da região metropolitana, nomes de estações tubo, terminais, nome das linhas alimentadoras, nome das linhas de ônibus) gerando diversas sobreposições que dificultam a visualização.

Quanto à representação da estrutura, está em planta e usando a base do mapa geopolítico de Curitiba. Por esse motivo, a área central, possui tamanho insuficiente para acomodar todas as informações. Observa-se novamente a existência de sobreposições que acabam atrapalhando a visualização das linhas de ônibus.

Quanto à apresentação da informação, o mapa em questão não combina layers (camadas) de informação. O mapa mistura muitas cores que não significam nada, não delimita áreas conhecidas (como bairros ou regionais). Possui uma grid de escala métrica (cada quadradinho representa $1 \mathrm{~km}^{2}$ ), mas não representa esta escala em tempo de caminhada a pé ou de ônibus.

As cores usadas no fundo dificultam a leitura e comprometem a orientação, pois confundem o usuário pela quantidade de nuances pastéis (verde claro, rosa claro, amarelo claro, lilás, bege). Cumpre mencionar ainda que muitas dessas cores foram utilizadas como decoração e não como informação.

Neste mapa, utilizaram-se famílias tipográficas como ARIAL e FUTURA, normal e em negrito (nomes dos terminais), itálico (nomes dos parques), caixa alta e caixa alta e baixa (legenda), não havendo consistência na representação. A mistura de tamanhos e fontes diferentes também confunde as informações. O tamanho utilizado para os nomes das linhas de ônibus varia, sendo muito pequeno nas linhas alimentadoras, estações tubo, parques e legenda. Já nos nomes das cidades metropolitanas é muito grande, principalmente se considerarmos que esta informação não é prioritária para os usuários e tira a atenção das informações necessárias (figura 07). 


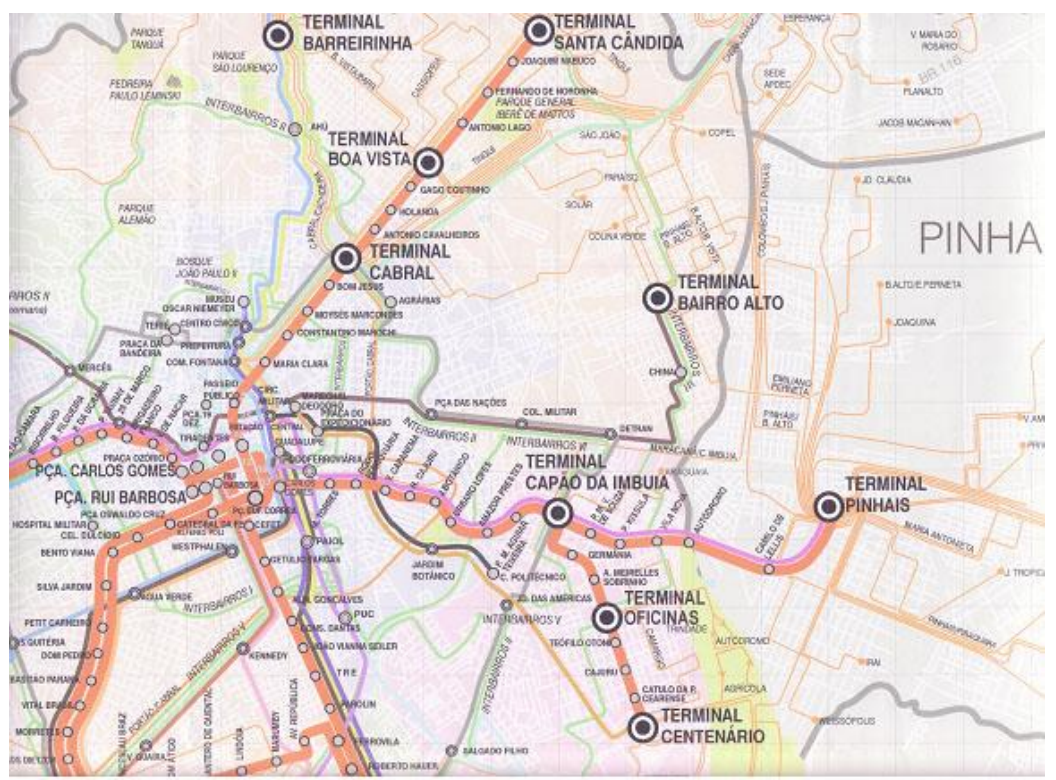

Figura 07: Excesso de variantes tipográficas nos rótulos usados no mapa RIT-URBS terminal

Por fim, o sinalizador de "você está aqui" está colocado sobre o nome do terminal de transporte coletivo específico e tem um círculo externo na cor amarelo com a frase escrita em letras azuis, quase imperceptíveis.

Em síntese, pode-se afirmar que o mapa RIT-URBS possui deficiências em todos os critérios considerados, desde o conteúdo até a apresentação da informação. Desse modo, pressupõe-se que o mesmo não cumpre sua função de auxiliar os usuários do transporte coletivo na tomada de decisões nos terminais urbanos. Esse pressuposto será verificado com a pesquisa realizada com usuários, cujos resultados são apresentados a seguir.

\section{Resultados da pesquisa com usuários}

Quando questionados sobre o que ou a quem consultam em caso de dúvidas sobre o transporte coletivo, descobrimos que a maioria dos usuários (53\%) pergunta aos funcionários do terminal, pois conforme alguns comentários anotados: "é mais rápido perguntar do que ficar procurando no mapa”. Além da maioria dos usuários que pergunta para funcionários, há uma parcela que consulta o site da URBS e PMC (11\%), liga e consulta o "156" (10\%) ou até pergunta para familiares ou amigos (6\%). Os resultados demonstraram que uma parcela muito pequena dos usuários consulta os subsistemas de informação do terminal. Apenas $6 \%$ dos entrevistados mencionaram consultar o mapa e $3 \%$ as placas dos pontos ou tabelas de horários (figura 08).

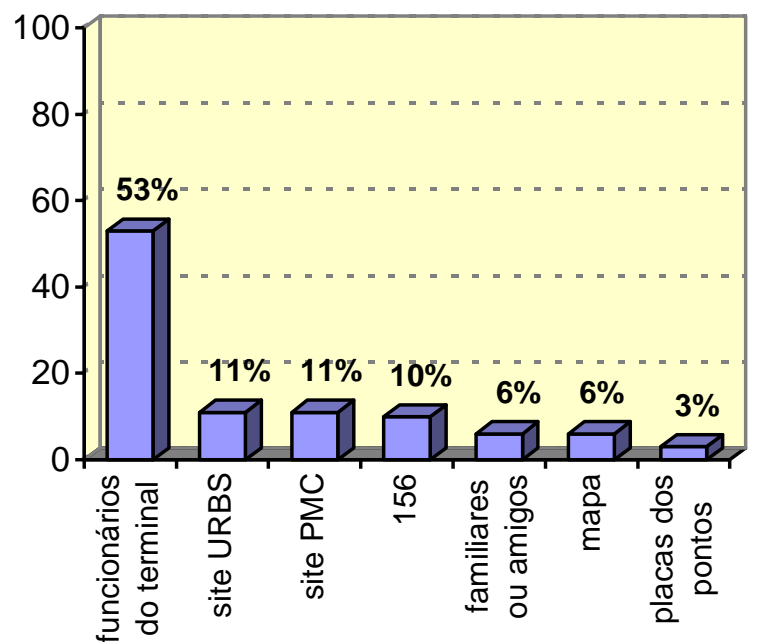


Figura 08: Fontes de consulta dos usuários em caso de dúvidas relacionadas ao sistema de transporte

Conforme mencionado anteriormente, a maioria dos usuários nunca o havia utilizado. As principais razões mencionadas foram: já conhecer o destino (23\%), não entender o mapa (20\%), não saber que o mapa existia (4\%), ou preferir consultar funcionários do terminal ou o "156" $(6 \%)$ (figura 09).

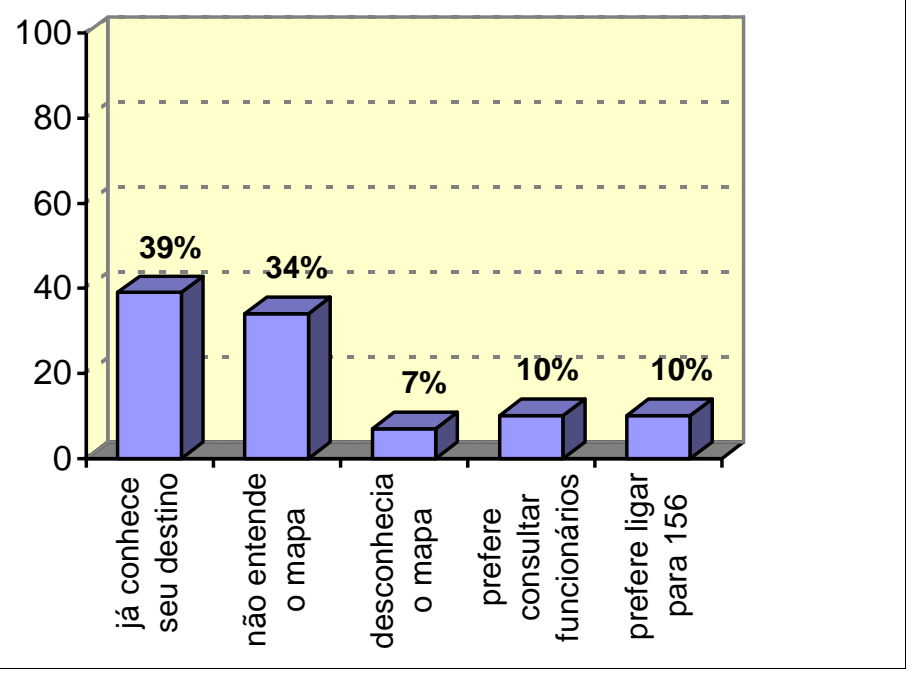

Figura 09: Principais razões para a não utilização do mapa RIT-URBS terminal pelos entrevistados

Antes das tarefas de orientação, perguntou-se para cada participante se ele sabia onde nós estávamos no mapa. A maioria dos entrevistados (76\%) respondeu que conseguiria fazer essa identificação. Entretanto quando colocados em frente ao mapa para executar a primeira tarefa (a de identificar onde estávamos no mapa - sinalizada pelo "você está aqui"), 37\% tiveram alta dificuldade, 36\% tiveram média dificuldade e $27 \%$ tiveram baixa dificuldade em executá-la, sendo que a maioria quase não encontrou o local que estava sinalizado no mapa com um adesivo circular. Criou-se uma expectativa irreal de entendimento do mapa, pois quando os usuários foram convidados a realizar a tarefa real usando o mapa comprovou-se a dificuldade de identificação do ponto em que se encontravam.

Já na segunda tarefa, perguntou-se para o usuário se ele saberia localizar o seu destino no mapa RIT-URBS. A maioria (57\%) dos entrevistados respondeu que conseguiria se localizar, mas quando colocados em frente ao mapa para executar a segunda tarefa (localizar o seu destino no mapa), 54\% dos entrevistados tiveram alta dificuldade em achar seu destino (não completaram a tarefa), $26 \%$ média dificuldade e $20 \%$ baixa dificuldade. Concluiu-se que a maioria não conseguiu terminar a tarefa de encontrar seu destino no mapa sem dificuldades. Comprova-se, portanto, que o mapa não é eficaz em sua principal tarefa: a de informar rota e ônibus para o destino de seus usuários.

Conforme opiniões colhidas junto aos usuários, o aspecto que mais prejudica a consulta do mapa é o excesso de informações no mesmo. Conforme um entrevistado: "este mapa para turista é um quebra cabeça!". Excesso de informações foi a resposta dada por 37\% dos usuários, 14\% ficam perdidos e confusos com as informações oferecidas pelo mapa, já $14 \%$ dos entrevistados acham que o mapa está incompleto e não contém as informações importantes sobre linhas de ônibus que deveriam estar no mapa. Outros entrevistados $(21 \%)$ responderam que cores ruins e letras pequenas demais é que atrapalham a visualização das informações. Houve ainda $7 \%$ dos entrevistados que disseram que a legenda está muito baixa e por isso não conseguem distinguir as linhas de ônibus. Outros entrevistados (3\%) responderam que o mapa em si está muito baixo, sendo difícil de achá-lo. Apenas $4 \%$ dos entrevistados mencionaram não terem encontrado deficiências no mapa. Esse conjunto de problemas faz com que o mapa acabe passando despercebido pela maioria dos usuários do transporte coletivo (figura 10). 


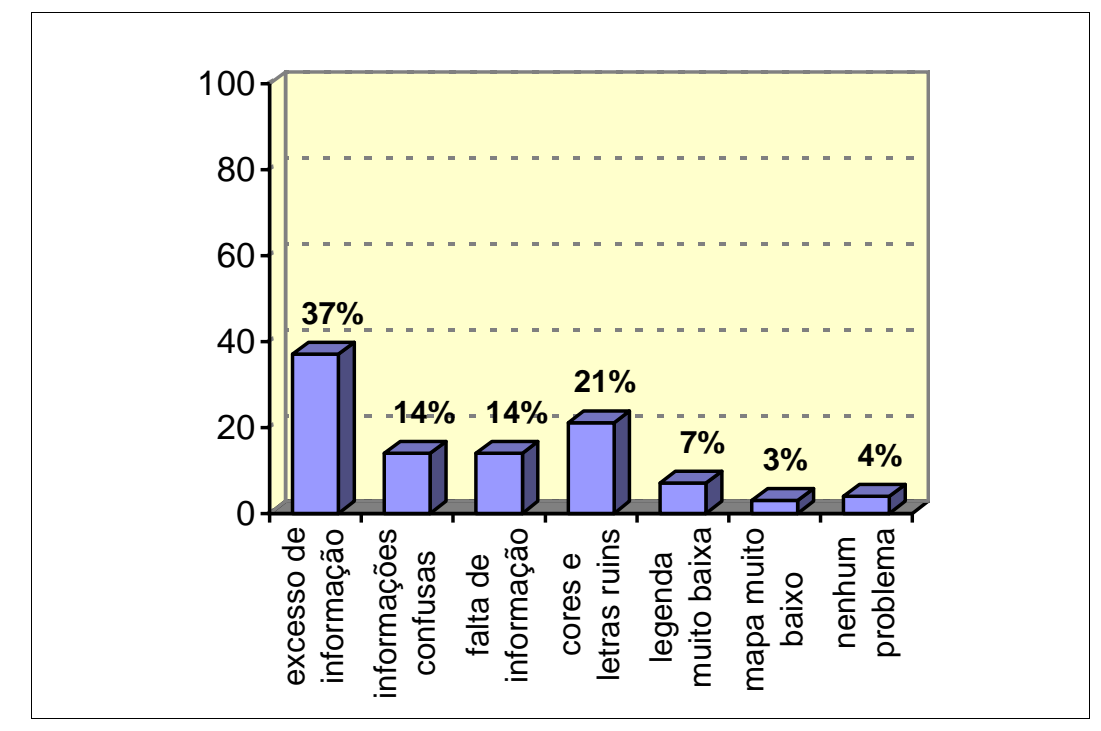

Figura 10: Aspectos que prejudicam a utilização do mapa RIT-URBS terminal

Após as críticas ao mapa, os participantes foram inquiridos sobre que mudanças considerariam necessárias. Nesse sentido, $21 \%$ comentaram que as informações devem ser simplificadas, $14 \%$ solicitaram aumento no tamanho das letras e $14 \%$ mapas específicos por região dos terminais. Outros $11 \%$ comentaram que se mudassem as cores o mapa ficaria melhor. Também $11 \%$ deslocariam a legenda para cima, para ficar mais fácil de consultá-la. Curiosamente, $9 \%$ dos entrevistados mencionaram que colocariam as linhas de ônibus no mapa (sem perceber que as linhas de ônibus já estão incluídas no mesmo). Outros $7 \%$ colocariam também os nomes das ruas e os pontos turísticos (tabela 01).

Tabela 01: Sugestões de mudança propostas pelos entrevistados para o mapa RIT-URBS terminal

\begin{tabular}{l|c}
\hline Sugestões & Respostas \\
\hline - Simplificar as informações & $21 \%$ \\
\hline - Aumentar o tamanho das letras & $14 \%$ \\
\hline - Tornar o mapa específico por região & $14 \%$ \\
\hline - Mudar as cores do mapa & $11 \%$ \\
\hline - Deslocar a legenda para cima & $11 \%$ \\
\hline - Adicionar as linhas de ônibus & $9 \%$ \\
\hline - Não modificaria nada nomes de ruas e pontos turísticos & $7 \%$ \\
\hline
\end{tabular}

Em síntese podemos verificar que o mapa RIT -URBS terminal necessita, conforme resultados da avaliação heurística e da pesquisa com usuários, eliminar as informações em excesso, em relação ao conteúdo. Quanto à organização, é importante dividir por áreas as informações. $\mathrm{Na}$ apresentação da informação, necessita-se de um novo layout com letras maiores destacando informações importantes, além da utilização de cores mais saturadas, ampliação da escala e maior equilíbrio visual entre as informações no mapa.

\section{Conclusões e desdobramentos}

Neste estudo, avaliamos o mapa RIT-URBS, disponível nos terminais de transporte coletivo da cidade de Curitiba, a partir de uma abordagem centrada no usuário. Em relação à metodologia utilizada, a conjugação de princípios de wayfinding e design da informação se mostrou diretamente aplicável à análise do mapa RIT-URBS, permitindo a identificação de deficiências 
informacionais e gráficas. Por outro lado, a participação dos usuários foi fundamental para confirmar algumas deficiências observadas em situação real de uso, além de entender melhor seu impacto sobre as tarefas de busca de informações e orientação nos terminais.

Esta pesquisa deixa como contribuição o entendimento sobre os processos envolvidos no uso do mapa de transporte coletivo RIT-URBS. Os resultados reforçam a importância da aplicação de princípios de design da informação para sistemas gráficos de orientação, visando evitar os problemas observados na pesquisa realizada com usuários do mapa em questão.

Confirma-se também a importância de que ao se criar um mapa de orientação deva-se pesquisar as características dos usuários que irão acessar as informações, estudar a quem o mapa vai orientar, para que se incluam informações necessárias que efetivamente venham a ajudar na tarefa de orientação espacial e não tornem o mapa apenas uma peça decorativa.

Como desdobramentos futuros deste estudo, podemos apontar a geração de diretrizes para o redesign do mapa analisado, assim como a realização de novos testes de usabilidade envolvendo o redesign do mapa proposto.

\section{Referências}

BENELLI, G. et al. (2001). Design concepts for learning spatial relationships. In Proceedings of SIGDOC'01, Santa Fé: ACM Press. p. 22-30.

CALVI, L. (1997). Navigation and disorientation: a case study. Journal of educational multimedia and hypermedia, 6(3-4). p. 305-320.

DEVLIN, A S.; BERNSTEIN, J. (1997). Interactive wayfinding: map style and effectiveness. Journal of environmental psychology, 17. p. 99-110.

HUNT, W. (1994). Basic principles of wayfinding. In Designing and planning environmental graphics. New York, Madison Square Press. p. 152-154.

KLIPPEL, A.; RICHTER, K.; BARKOWSKY, T.; FREKSA, C. (2005). The Cognitive Reality of Schematic Maps. In MENG et al. (Eds.) Map-based mobile services - theories, methods and implementations. Berlin: Springer. p. 57-74.

LYNCH, K. (2006). A Imagem da Cidade. São Paulo: Martins Fontes Editora.

MIJKSENAAR, P. (1999). Maps as public graphics: about science and craft, curiosity and passion. In Visual information for everyday use: design and research perspectives. London: Taylor \& Francis. p. 211-224.

O’NEILL, M. J. (1994). Plans and signage: a behavioural research perspective. In Proceedings of Public Graphics. The Netherlands.

PASSINI, R. (1994). Graphics and architecture of wayfinding. In Proceedings of Public Graphics. The Netherlands.

PETTERSON, R. (2007). It Depends: ID - Principles and Guidelines. Tullinge: Institute for Infology. PHEASANT, S. (1987). Ergonomics: standards and guidelines for designers. London, British Standards.

SATALICH, G. A. (1995). Navigation and wayfinding in virtual reality: finding proper tools and cues to enhance navigation awareness. <http://www.hitl.washington.edu/publications/1995pub.html>. Acesso em: 20/01/2008.

SPINILLO, C. G. (2007). Sistemas gráficos de orientação. Material didático do Curso de Especialização de Design Informacional. Curitiba: PUC-PR.

VENEMANS, Piet. (1994). Wayfinding and orientation, sign systems and buildings. In Proceedings of Public Graphics. The Netherlands. p. 21.1-21.11.

\section{Sobre os autores (nota biográfica)}

Audrey C. C. Sommavilla é graduada no Curso Superior de Pintura pela Escola de Música e Belas Artes do Paraná (2003), especialista em Design Informacional pela PUC-PR (2008). Desenhista do IPPUC - Instituto de Pesquisa e Planejamento Urbano de Curitiba, onde sua principal área de atuação é no design informacional de equipamentos públicos e no 
desenvolvimento de projetos de mobiliário urbano.

<audrey@ippuc.org.br>

Stephania Padovani é graduada em Desenho Industrial pela ESDI-UERJ (1996), mestre em Design pela PUC-RJ (1998) e doutora em Ergonomia Cognitiva pela Loughborough University / Inglaterra (2001). É bolsista de Produtividade em Pesquisa do CNPq [nível 2], professora e pesquisadora do Departamento de Design da UFPR. Suas principais áreas de atuação são ergonomia da interação humano-computador e design da informação, com enfoque nos temas de hipermídia, usabilidade de interfaces e métodos de design centrado no usuário.

<s_padovani2@yahoo.co.uk> 